\title{
Requerimento de irrigação para a laranja em cenários climáticos futuros no Norte e Noroeste Fluminense
}

\author{
Evaldo de Paiva Lima ${ }^{1(*)}$ e Rosandro Boligon Minuzzi ${ }^{2}$ \\ ${ }^{1}$ Empresa Brasileira de Pesquisa Agropecuária (Embrapa Solos/UEP-Recife). Rua Antônio Falcão, 402, CEP 51020-240 Recife, PE. E-mail: evaldo.lima@ \\ embrapa.br \\ ${ }^{2}$ Universidade Federal de Santa Catarina (UFSC), Rodovia Admar Gonzaga, 1346, CEP 88034-001 Florianópolis, SC. E-mail: rosandro.minuzzi@ufsc.br \\ ${ }^{(*)}$ Autor para correspondência.
}

\section{INFORMAÇÕES}

\section{História do artigo:}

Recebido em 13 de setembro de 2019

Aceito em 4 de março de 2020

Termos para indexação:

ciclo produtivo

variedades

manejo de irrigação

\section{RESUMO}

Este estudo teve o objetivo de determinar o requerimento de água provindo de irrigação para diferentes variedades de laranjeira e cenários climáticos nas mesorregiões Norte e Noroeste do estado do Rio de Janeiro. Dados climáticos dos municípios de Campos, Itaperuna e Santo Antônio de Pádua foram utilizados no software Cropwat 8.0 para simular o requerimento de água para irrigação por dois métodos, para o clima atual (1981 a 2010) e nos cenários climáticos baseados nas projeções de curto (2016-2035) e médio (2046-2065) prazos dos cenários RCP4.5 e RCP8.5 do Painel Intergovernamental sobre Mudança Climática (IPCC, sigla em inglês). Os resultados mostraram tendências de aumento no requerimento de água para irrigação nos três grupos de variedades de laranjeira, sendo que os maiores valores ocorreram no grupo da variedade ‘tardia' e no município de Santo Antônio de Pádua, tanto a curto como de médio prazos. Porém, considerando os inexpressivos aumentos de irrigação em relação a duração dos ciclos das três variedades de laranjeira, o clima projetado para a região de estudo ainda será suficiente para satisfazer as necessidades de água para os três grupos de variedades de laranjeira.

(c) 2020 SBAgro. Todos os direitos reservados.

\section{Introdução}

A irrigação é uma operação agrícola que fornece água para as plantas nas regiões mais secas ou se conta com o fornecimento suplementar nas épocas de estiagem das regiões mais úmidas. A irrigação também pode ser benéfica na redução da temperatura do ar e das plantas bem como na diminuição dos efeitos de geadas. Desse modo, a irrigação provê um importante grau de estabilidade para a produção de alimentos, visto que os efeitos das adversi- dades meteorológicas podem ser minimizadas.

O manejo da irrigação, que é dependente das condições meteorológicas por meio da precipitação e da evapotranspiração, serve para determinar a quantidade de água a ser suprida ao solo de modo que as necessidades hídricas das culturas sejam plenamente atendidas. A quantificação da evapotranspiração é importante, principalmente, no dimensionamento de projetos e no manejo da irrigação, pois, conhecendo-se a perda de água pelas culturas, é possível determinar quanto irrigar. Além disso, o conhe- 
cimento do momento correto de irrigar é de suma importância para se propor um manejo adequado, de modo a dotar o solo de água facilmente utilizável pelas plantas, evitando-se aplicações deficientes ou excessivas de água, as quais podem acarretar doenças, lixiviação de nutrientes e perdas de solo, além do gasto adicional de energia e insumos.

A disponibilidade de água para irrigação em todo o mundo tem decrescido nos últimos anos devido a uma combinação de secas frequentes e competição por recursos hídricos entre os usuários agrícolas, industriais e urbanos. Além disso, grandes áreas agrícolas enfrentam de moderada a significativa redução na precipitação como resultaa do das mudanças climáticas globais (Ortega-Farias et al., 2009). ANA (2017) complementa dizendo que os padrões de distribuição das chuvas variam naturalmente, porém nos últimos anos têm sido observados eventos extremos de seu excesso ou escassez, e alterações nos padrões da precipitação no Brasil.

Os efeitos das mudanças climáticas globais, cujos impactos vêm sendo estudados e descritos regional e setorialmente, não devem ser ignorados. Apesar de haver incertezas quanto às tendências previstas nos diferentes modelos, os cenários climáticos geralmente apontam para situações críticas de estresse hídrico e de intensificação de eventos relacionados a secas e cheias. Os prejuízos que podem gerar no setor de recursos hídricos quanto a danos ambientais e humanos, além de sociais e econômicos que levem a conflitos pelo uso da água, já são suficientes para a adoção de medidas preventivas e adaptativas. Para tanto, o foco no planejamento e na implementação de ações planejadas deve ser a regra na antecipação das adversidades e dos impactos (ANA, 2017).

Os cenários climáticos são representações do clima futuro, baseadas em um conjunto de suposições que incluem tendências futuras de demanda energética, emissões de gases de efeito estufa, mudanças no uso do solo e aproximações nas leis que regem o comportamento do sistema climático sobre grandes períodos de tempo, como resultante das atividades humanas (Hamada et al., 2008). El Chami \& Daccache (2015) acrescentam que os cenários climáticos futuros mostram redução nas áreas de cultivo e no rendimento de culturas de sequeiro, com altas perdas econômicas e a necessidade de irrigação como medida de adaptação.

A citricultura, que é cultivada tanto no modo sequeiro como no irrigado, é uma importante atividade do agronegócio brasileiro. Zulian et al. (2013) relatam que a citricultura é suscetível as mudanças climáticas e as doenças que afetam as frutas. Essas situações interferem na produção, no preço de mercado e, consequentemente, em todo andamento da atividade. Neves et al. (2010) citam, como exemplo, que a ocorrência de chuvas mais escassas, nos últimos anos, na porção norte do estado de São Paulo tem feito com que os pomares citrícolas dessa região tenham adotado a irrigação como forma de garantia da produção. Acrescentam que essa situação é diferente do que ocorria cerca de três décadas atrás.

Existem várias frutas que pertencem ao grupo da citricultura, do gênero Citrus, sendo as principais espécies a laranja, a tangerina e o limão. De acordo com EMATER-RIO (2017), os Citrus representam 27\% do faturamento global do setor de fruticultura no estado do Rio de Janeiro, ficando atrás apenas da cultura do abacaxi (30\%). A citricultura Fluminense obteve receita de R\$155,7 milhões no ano de 2017, sendo cultivada em uma área de 7.427 hectares por aproximadamente 1500 produtores. A laranja é a principal fruta citrícola produzida no Estado, com $54 \%$ da produção total do segmento, seguida do limão (25\%) e da tangerina (21\%).

As pesquisas sobre a temática 'mudanças climáticas' associadas com irrigação são relativamente recentes, de maneira que, a bibliografia atesta poucos estudos (Finger et al., 2011; Minuzzi et al.; 2017; Minuzzi \& Caramori, 2010), principalmente no Brasil e aplicada para frutíferas. Assim, diante das questões apresentadas, o objetivo deste estudo é determinar o requerimento de água provindo de irrigação para diferentes variedades de laranjeira e cenários climáticos nas mesorregiões Norte e Noroeste do estado do Rio de Janeiro.

\section{Materiais e Métodos}

Utilizaram-se médias climáticas mensais de precipitação, temperatura mínima e máxima do ar, obtidas da série histórica de 1981 a 2010, das estações meteorológicas situadas em Campos dos Goytacazes, Itaperuna, Santo Antônio de Pádua (Figura 1) que ficam localizadas, respectivamente, no Norte e Noroeste Fluminense (Figura 2), e que pertencem ao Instituto Nacional de Meteorologia (INMET). Na Tabela 1 contém as informações relativas a cada uma das estações.

O requerimento de água para irrigação foi obtido pela diferença entre a evapotranspiração da cultura (ETc) e a precipitação efetiva $\left(\mathrm{P}_{\mathrm{ef}}\right)$ e a irrigação líquida total para o ciclo da laranjeira, utilizando para as estimativas o software Cropwat 8.0.

Para a determinação da irrigação líquida total durante todo o ciclo da laranja, adotou-se os seguintes critérios quanto ao planejamento da irrigação: 1) irrigar quando a água facilmente disponível (AFD) estiver próxima a zero; e 2) durante cada irrigação aplicar uma lâmina de água variável o suficiente para atingir a capacidade de campo do solo.

A seguir, constam as principais informações exigidas no Cropwat 8.0 e estabelecidas para este estudo no que tan- 
Figura 1. Médias climáticas mensais de precipitação $(\mathrm{mm})$, temperatura mínima e máxima do ar $\left({ }^{\circ} \mathrm{C}\right)$ para Campos dos Goytacazes (a), Itaperuna (b) e Santo Antônio de Pádua (c).

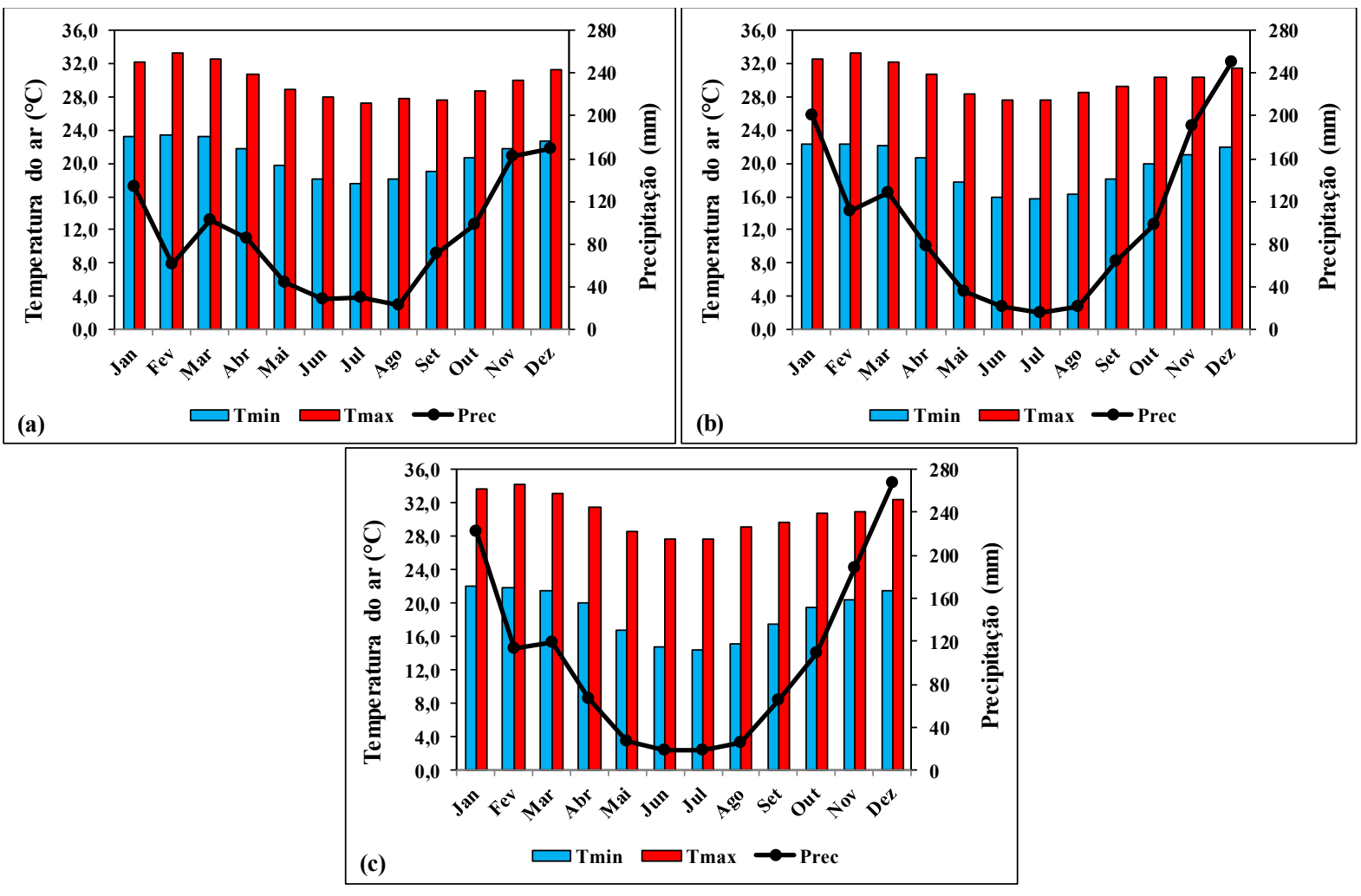

Figura 2. Localização das estações utilizadas no estudo.
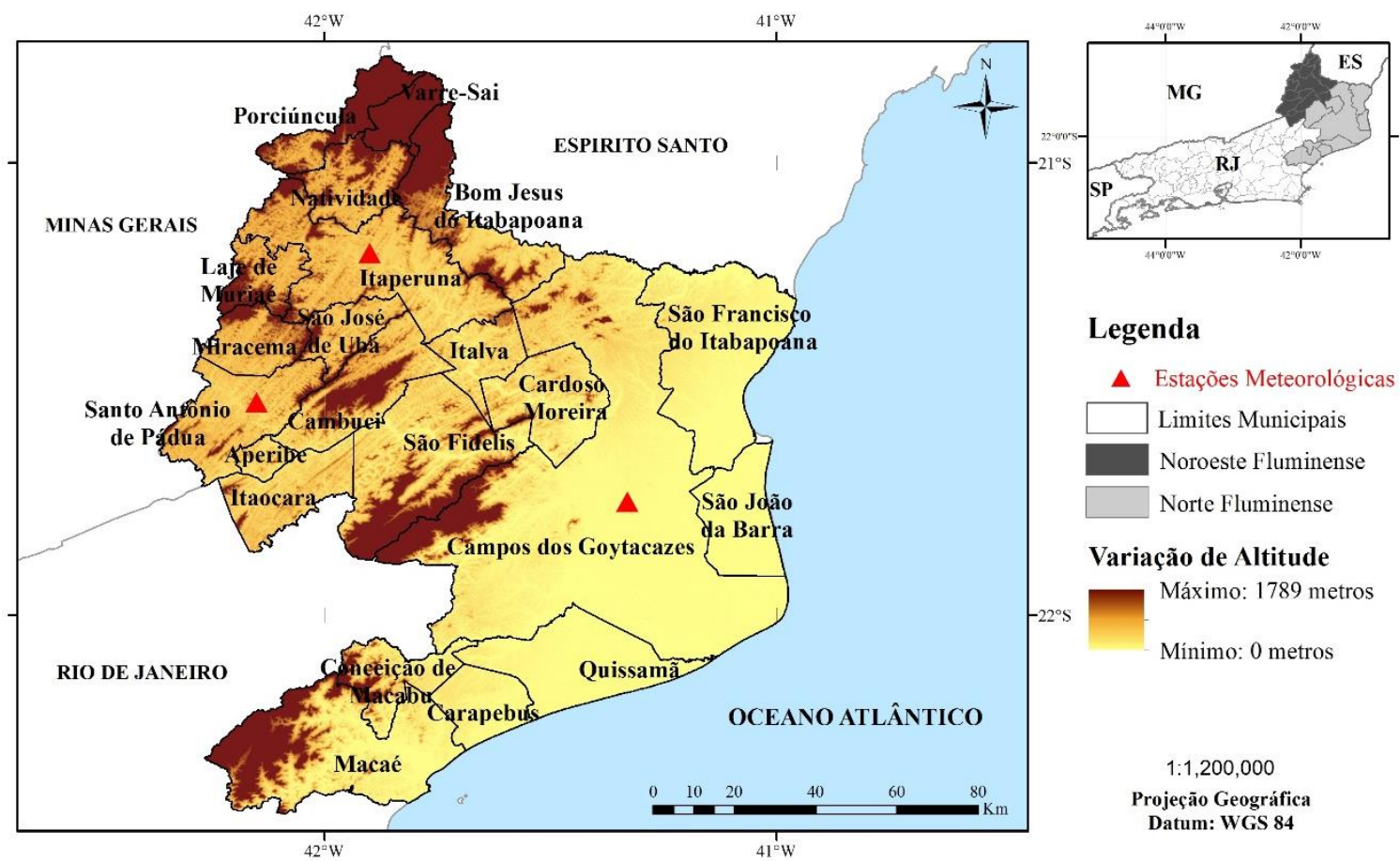

\section{Legenda}

\ Estações Meteorológicas

Limites Municipais

Noroeste Fluminense

Norte Fluminense

Variação de Altitude

Máximo: 1789 metros

Mínimo: 0 metros

$1: 1,200,000$

Projeção Geográfica

Datum: WGS 84 
Tabela 1. Coordenadas geográficas das estações

\begin{tabular}{lcccc} 
Municípios & Código & Latitude $\left({ }^{\circ}\right)$ & Longitude $\left(^{\circ}\right)$ & Altitude (m) \\
Campos dos Goytacazes & 83698 & $-21,75$ & $-41,33$ & 11,20 \\
Itaperuna & 83695 & $-21,20$ & $-41,90$ & 123,59 \\
Santo Antônio de Pádua & 83805 & $-21,53$ & $-42,15$ & 95,00 \\
\hline
\end{tabular}

ge aos parâmetros meteorológicos, fenológicos da cultura e edafológicos.

A evapotranspiração de referência (ETo) foi estimada pelo método de Penman-Monteith (PM-Padrão FAO), utilizando somente dados de temperatura mínima e máxima do ar. As demais variáveis necessárias para a estimativa de ETo por PM-Padrão FAO, foram obtidas conforme metodologias proposta por Allen et al. (1998). Para a precipitação efetiva foi considerado $73 \%$ do registrado pelo pluviógrafo (Freitas et al., 2016).

O início do ciclo foi considerado o florescimento, tendo a data representativa de $1^{\circ}$ de outubro, visto que, na maioria das variedades, o ciclo produtivo tem início na primavera. Para o encerramento do ciclo, e consequentemente, a duração, foi considerado três períodos em função da época de maturação de diferentes variedades (Mattos Júnior et al., 2005): precoce (duração do ciclo de 6 meses); meia estação (duração do ciclo de 7 meses) e tardia (duração do ciclo de 9 meses).

O coeficiente de cultura $(\mathrm{Kc})$ foi de 0,65; 0,70 e 0,60 e a fração de água facilmente disponível foi de 0,70; 0,30 e 0,70 para, respectivamente, as fases inicial (florescimento), intermediária e final (maturação), conforme Pereira (2011). o fator de resposta na produtividade variou de 0,8 a 1,1 de acordo com Doorenbos \& Kassan (2000).

Para os dados edafológicos foi considerado solo de textura média (médio armazenamento), com a taxa de infiltração máxima de chuva de $40 \mathrm{~mm}$.dia ${ }^{-1}$ e CADp (capacidade de água disponível do pomar) de $294 \mathrm{~mm}$, obtido de acordo com a Equação 1 apresentada por Pereira (2011):

$$
\mathrm{CADp}=\mathrm{CADr} \cdot \mathrm{V}_{\text {ef }}
$$

onde, CADr é a capacidade de água disponível de referência de $140 \mathrm{~mm}$ para solos de textura média (Pereira, 2011) e $\mathrm{V}_{\mathrm{ef}}$ é o volume efetivo do solo irrigado, igual a 2,1 $\mathrm{m}^{3}$.árvore ${ }^{-1}$, determinado pela Equação 2.

$$
\mathrm{V}_{\mathrm{ef}}=\mathrm{As} \cdot \mathrm{Z}_{\mathrm{ef}}
$$

onde, As é área superficial do solo realmente ocupada pelas raízes $\left(3 \mathrm{~m}^{2}\right)$ e $\mathrm{Z}_{\text {ef }}$ é a profundidade efetiva do sistema radi$\operatorname{cular}(0,7 \mathrm{~m})$.

As simulações consideraram o cenário climático atual
Tabela 2. Desvios trimestrais de temperatura média do ar $\left({ }^{\circ} \mathrm{C}\right)$, baseados no percentil 50\% projetados para a região em estudo, pelos cenários RCP4.5 e RCP 8.5 do IPCC no curto (2016-2035) e médio (2046-2065) prazos

\begin{tabular}{lcccc}
\hline RCP 4.5 & Dez-Fev & Mar-Mai & Jun-Ago & Set-Nov \\
\hline Curto prazo & 0,8 & 0,8 & 0,8 & 0,8 \\
\hline Médio prazo & 1,3 & 1,3 & 1,3 & 1,5 \\
\hline RCP 8.5 & & & & \\
\hline Curto prazo & 0,8 & 0,8 & 0,8 & 1,0 \\
\hline Médio prazo & 1,7 & 1,7 & 1,7 & 2,5 \\
\hline
\end{tabular}

Fonte: Adaptado de IPCC (2013).

(1981 a 2010) e cenários futuros apresentados no último relatório do Painel Intergovernamental sobre Mudança Climática (IPCC, 2013) baseadas no valor do percentil 50\% da distribuição do 'ensemble' entre os modelos utilizados para gerar os cenários RCP4.5 e RCP8.5, à curto prazo (20162035) e a médio prazo (2046-2065). o primeiro cenário é relativamente mais otimista, por considerar que serão tomadas medidas para reduzir a emissão de $\mathrm{CO}_{2}$, ao contrário do RCP8.5 que não serão tomadas medidas de mitigação contra as mudanças climáticas. Os desvios de temperatura do ar para a região em estudo são apresentados na Tabela 2. Para a precipitação não será considerado nenhum desvio, pois as diferenças médias de 20 anos (1986 a 2005) do percentil são menores do que o desvio padrão da variabilidade natural atual estimada pelo modelo das diferenças médias de 20 anos.

\section{Resultados e Discussão}

O requerimento de água para irrigação, dado pela difee rença entre ETc e Pef, e a irrigação líquida total para três grupos de variedades de laranjeira estimados para o clima atual (referência) e respectivos desvios para cenários climáticos a curto e médio prazos de acordo com as projeções do RCP4.5, que é um cenário climático mais otimista quando comparado ao RCP8.5, para três localidades do Norte e Noroeste Fluminense são apresentados na Tabela 3.

A diferença entre os resultados apresentados é que o requerimento de água para irrigação considera somente as condições climáticas e da cultura, enquanto que a irrigação líquida total acrescenta-se as condições do solo. A irrigação líquida total é a lâmina de água que efetivamente 
deverá estar disponível para infiltrar no solo e conforme observa-se na Tabela 3, com exceção em Santo Antônio de Pádua no grupo da variedade 'tardia', possuiu valores iguais a zero $(0,0 \mathrm{~mm})$, tanto para o clima atual como para os cenários climáticos de curto e médio prazos. Esses resultados concordam com os encontrados no sul do Brasil por Minuzzi et al. (2017), e isso indica que para os três grupos de variedades de laranjeira, com exceção da variedade comentada anteriormente, não existe a necessidade de suplementação de água, nos períodos de 2016-2035 e 20462065, considerando-se solos de textura média.

De maneira geral, observa-se um aumento no requerimento de água para irrigação nos cenários futuros. A explicação está na ausência de desvios futuros da precipitação juntamente com o aumento da temperatura para todos os cenários que resultará numa maior evapotranspiração, sendo maior, conforme aumenta a duração do ciclo das variedades de laranjeira. Quando se compara as três localidades, em Santo Antônio de Pádua os valores do requerimento de água foram superiores aos de Campos e Itaperuna nos três grupos de variedades. A título de exemplo, e considerando o clima atual, no grupo da variedade 'tardia' o requerimento em Santo Antônio de Pádua $(219,7 \mathrm{~mm})$ chegou a ser 55,2 mm maior do que em Itaperuna (164,5 mm).

Observa-se ainda na Tabela 3, em ambos os cenários, que o requerimento de água para irrigação apresentou tendências positivas para os três grupos de variedades de laranjeira, sendo que os maiores valores ocorreram no grupo da variedade 'Tardia'. Nesse grupo, os valores do requerimento de água foram de 10,0 e 16,5 mm para Campos; 9,7 e 16,3 mm para Itaperuna e; 10,9 e 21,1 mm para Santo Antônio de Pádua, respectivamente, no curto e médio prazos. Levando-se em conta o cenário de médio prazo, um agricultor que está em Santo Antônio de Pádua precisará irrigar $4,8 \mathrm{~mm}$ a mais do que um agricultor que está em Itaperuna.

Minuzzi et al. (2017) analisaram o desempenho agronômico da soja cultivada no sul do Brasil para tanto utilizaram dados climáticos de três municípios localizados nas principais regiões produtoras de soja e simularam a duração do ciclo, produtividade, eficiência do uso da água na produtividade da água evapotranspirada (EUA), requerimento de irrigação líquida e o índice de colheita ajustado em diferentes cenários climáticos, baseados nas projeções em curto prazo (2016-2035) e médio prazo (2046-2065) do cenário RCP4.5 do IPCC. Esses autores observaram que a duração do ciclo da soja tende a diminuir quanto mais frio for a localidade e, também que a produtividade e a EUA devem aumentar, mesmo que não haja requerimento de irrigação nos cenários climáticos futuros.

Apesar da soja não ser uma cultura perene, foi dado destaque ao trabalho anterior porque existem poucos trabalhos associando o efeito das mudanças climáticas em culturas frutíferas.

Na Tabela 4 são apresentados o requerimento de água para irrigação e a irrigação líquida total para três grupos de variedades de laranjeira (precoce, meia estação e tardia) estimados para o clima atual e respectivos desvios para cenários climáticos a curto e médio prazos de acordo com as projeções do RCP8.5.

Na Tabela 4 observa-se que, a irrigação líquida total também possuiu valores iguais a zero nas três localidades, com exceção em Santo Antônio de Pádua no grupo da variedade 'Tardia', tanto para o clima atual como para os cenários climáticos de curto e médio prazos. Também verifica-se, de modo geral, que os requerimentos de água para irrigação são maiores nas projeções do RCP8.5 do que as projeções do RCP4.5 (Tabela 3), sendo o esperado, em

Tabela 3. Requerimento de água para irrigação $(\mathrm{mm})$ e a irrigação líquida total $(\mathrm{mm}) 1$ para três grupos de variedades de laranjeira estimados para o clima atual e respectivos desvios para cenários climáticos a curto (2016-2035) e médio (2046-2065) prazos de acordo com as projeções do RCP4.5.

\begin{tabular}{|c|c|c|c|}
\hline Variedade & Clima atual & Curto prazo & Médio prazo \\
\hline \multicolumn{4}{|c|}{ Campos dos Goytacazes } \\
\hline Precoce & $85,9 / 0,0$ & $+5,7 / 0,0$ & $+9,3 / 0,0$ \\
\hline Meia estação & $100,4 / 0,0$ & $+6,8 / 0,0$ & $+12,1 / 0,0$ \\
\hline Tardia & $169,1 / 0,0$ & $+10,0 / 0,0$ & $+16,5 / 0,0$ \\
\hline \multicolumn{4}{|l|}{ Itaperuna } \\
\hline Precoce & $48,6 / 0,0$ & $+5,1 / 0,0$ & $+8,7 / 0,0$ \\
\hline Meia estação & $73,4 / 0,0$ & $+6,7 / 0,0$ & $+11,5 / 0,0$ \\
\hline Tardia & $164,5 / 0,0$ & $+9,7 / 0,0$ & $+16,3 / 0,0$ \\
\hline \multicolumn{4}{|c|}{ Santo Antônio de Pádua } \\
\hline Precoce & $69,0 / 0,0$ & $+6,0 / 0,0$ & $+12,5 / 0,0$ \\
\hline Meia estação & $110,9 / 0,0$ & $+8,0 / 0,0$ & $+15,9 / 0,0$ \\
\hline Tardia & $219,7 / 121,8$ & $+10,9 /+0,7$ & $+21,1 /+0,7$ \\
\hline
\end{tabular}

${ }^{1}$ Primeiro valor refere-se a irrigação requerida por ETc- ${ }_{\mathrm{ef}}$ e o segundo valor a irrigação líquida. 
consideração que aquele é um cenário mais pessimista que o RCP 4.5, com maiores aumento da temperatura do ar, ou seja, maior evapotranspiração. Isso indica que os três grupos de variedades de laranjeira, num cenário climático menos otimista, precisarão de mais água durante o ciclo produtivo.

Observa-se ainda que, o requerimento de água para irrigação apresentou tendências positivas para os três grupos de variedades de laranjeira, sendo que os maiores valores também ocorreram no grupo da variedade 'tardia'. Nesse grupo, os valores do requerimento de água foram de 10,3 e 23,0 mm para Campos; 10,0 e 22,6 mm para Itaperuna e; 11,4 e 26,1 mm para Santo Antônio de Pádua, respectivamente, no curto e médio prazos (Tabela 4).

Apesar do aumento no requerimento de irrigação em ambos os cenários, pode-se considerar que não são valores expressivos, visto que são válidos para todo o ciclo da cultura que varia de seis a nove meses. Assim, presume-se que, apesar desta tendência de aumento no requerimento de água da laranja, provavelmente não venha a resultar em redução na produtividade da cultura e, se houver, será insignificante. Por isso, numa relação custo e benefício, a implantação de um sistema de irrigação não compensaria eventuais pequenas perdas decorrente de redução na produtividade da laranja em função do déficit hídrico.

Mesmo que não sejam resultados muito alarmantes, uma das medidas que podem ser tomadas para minimizar ou evitar os efeitos das mudanças climáticos no cultivo agrícola é o melhoramento genético, conforme indicaram Pommer \& Barbosa (2009) para frutíferas de clima quente como a laranjeira.

Dois fatores podem ser apontados para que a laranjeira não venha a requerer quantidades muito expressivas de água em cenários futuros: a profundidade do sistema ra- dicular e grande parte da duração do ciclo produtivo estar centrado no período chuvoso da região. Quanto ao sistema radicular, é um detalhe interessante que provavelmente venha ser o diferencial, se o contexto deste estudo, viesse a ser aplicado para uma cultura anual. Entretanto, a duração do ciclo produtivo, justifica o maior requerimento de irrigação nas cultivares tardias (9 meses), isto é, os estádios fenológicos finais do ciclo já estariam no período seco da região. Enquanto uma cultivar de ciclo precoce tem o seu ciclo produtivo totalmente dentro dos meses do período chuvoso que vai de outubro a março (Minuzzi et al., 2007).

Finger et al. (2011) avaliaram a irrigação como estratégia de adaptação diante dos possíveis impactos das mudanças climáticas na produtividade do milho na região do Planalto Suíço, levando em conta diferentes cenários climáticos (aumentos na temperatura do ar, na precipitação e na concentração de $\mathrm{CO}_{2}$ para 2030 e 2050) e de preços de mercado. Mesmo que a adoção de irrigação do milho leve a produtividades maiores e menos variáveis no futuro, os benefícios econômicos da adoção dessa atividade agrícola devem ser pequenas.

Numa situação atual que aponta à agricultura irrigada como responsável pelo uso de aproximadamente $70 \%$ da água total no mundo, a possibilidade de ocorrência futura de aumento no requerimento de água por irrigação na região em estudo é uma informação preocupante, diante de um panorama ambiental e social futuro que remete ao aumento do uso da água, devido ao aumento populacional. Este cenário vai demandar em maior necessidade por alimentos, bem como ao aumento de áreas irrigadas. Por isso, a exigência de medidas para otimizar a produção agrícola diante de cenários climáticos futuros, como o uso de variedades mais resistentes ao déficit hídrico ou incrementar a

Tabela 4. Requerimento de água para irrigação $(\mathrm{mm})$ e a irrigação líquida total $(\mathrm{mm})^{1}$ para três grupos de variedades de laranjeira estimados para o clima atual e respectivos desvios para cenários climáticos a curto (2016-2035) e médio (2046-2065) prazos de acordo com as projeções do RCP8.5

\begin{tabular}{|c|c|c|c|}
\hline Variedade & Clima atual & Curto prazo & Médio prazo \\
\hline \multicolumn{4}{|c|}{ Campos dos Goytacazes } \\
\hline Precoce & $85,9 / 0,0$ & $+6,0 / 0,0$ & $+13,9 / 0,0$ \\
\hline Meia estação & $100,4 / 0,0$ & $+7,5 / 0,0$ & $+17,1 / 0,0$ \\
\hline Tardia & $169,1 / 0,0$ & $+10,3 / 0,0$ & $+23,0 / 0,0$ \\
\hline \multicolumn{4}{|l|}{ Itaperuna } \\
\hline Precoce & $48,6 / 0,0$ & $+5,5 / 0,0$ & $+13,0 / 0,0$ \\
\hline Meia estação & $73,4 / 0,0$ & $+7,1 / 0,0$ & $+16,4 / 0,0$ \\
\hline Tardia & $164,5 / 0,0$ & $+10,0 / 0,0$ & $+22,6 / 0,0$ \\
\hline \multicolumn{4}{|c|}{ Santo Antônio de Pádua } \\
\hline Precoce & $69,0 / 0,0$ & $+6,5 / 0,0$ & $+15,7 / 0,0$ \\
\hline Meia estação & $110,9 / 0,0$ & $+8,4 / 0,0$ & $+19,6 / 0,0$ \\
\hline Tardia & $219,7 / 121,8$ & $+11,4 /+0,7$ & $+26,1 /+1,8$ \\
\hline
\end{tabular}

${ }^{1}$ Primeiro valor refere-se a irrigação requerida por ETc- $\mathrm{P}_{\mathrm{ef}}$ e o segundo valor a irrigação líquida. 
tecnologia de irrigação que resultará numa diminuição no uso de água na agricultura (Wu et al., 2010).

\section{Conclusões}

Há um aumento no requerimento de água para irrigação quanto maior for a duração do ciclo das variedades de laranjeira cultivadas na região em estudo.

o clima projetado para a região de estudo ainda será suficiente para satisfazer as necessidades de água da frutífera mesmo considerando os inexpressivos aumentos de irrigação em relação a duração dos ciclos das três variedades de laranjeira.

\section{Agradecimentos}

Ao fomento do projeto FAPERJ no E-26/112.445/2012: Climatologia e cenários futuros no requerimento de água para irrigação de culturas frutíferas nas mesorregiões Norte e Noroeste do estado do Rio de Janeiro. E também ao INMET, pela disponibilização de dados meteorológicos.

\section{Referências}

ALLEN, R. G.; PEREIRA, L. S.; RAES, D.; SMITH, M. Crop evapotranspiration: guidelines for computing crop water requirements. Rome: FAO, 1998. 300 p. (FAO - Irrigation and Drainage Paper, 56).

ANA - Agência Nacional de Águas. Conjuntura dos recursos hídricos no Brasil 2017. Brasília, 2017. Disponível em: <http://www.snirh.gov. $\mathrm{br} / \mathrm{portal} / \mathrm{snirh} / \mathrm{centrais}-\mathrm{de}-\mathrm{conteudos} /$ conjuntura-dos-recursoshidricos/conj2017_rel-1.pdf>. Acesso em: 20 mai. 2019.

DOORENBOS, J.; KASSAN, A. H. Efeito da água no rendimento das culturas. 2.ed. Estudos FAO: Irrigação e drenagem n. 33, 2000. 221 p. (Traduzido por GHEYI, H. R.; SOUSA, A. A. de; DAMASCENO, F. A. V.; MEDEIROS, J. F. de - UFPB)

EL CHAMI, D.; DACCACHE, A. Assessing sustainability of winter wheat production under climate change scenarios in a humid climate - An integrated modelling framework. Agricultural Systems, v. 140, p. 19-25, 2015.

EMATER-RIO - Empresa de Assistência Técnica e Extensão Rural do Estado do Rio de Janeiro. Acompanhamento Sistemático da Produção Agrícola 2017. Rio de Janeiro, 2017. Disponível em: <http://www. emater.rj.gov.br/areaTecnica/RELCUL2017.pdf>. Acesso em: 20 mai. 2019.

FINGER, R.; HEDIGER, W.; SCHMID, S. Irrigation as adaptation strategy to climate change - a biophysical and economic appraisal for Swiss maize production. Climatic Change, v. 105, p. 509-528, 2011.
FREITAS, J. P. O.; DIAS, H. C. T.; SILVA, E.; TONELLO, K. C. Net precipitation in a semideciduos Forest fragment in Viçosa City, MG. Revista Árvore, v. 40, n. 5, p. 793-801. 2016.

HAMADA, E.; GONÇALVES, R. R. V.; ORSINI, J. A. M.; GHINI, R. Cenários climáticos futuros para o Brasil. In: GHINI, R.; HAMADA, E. (eds.) Mudanças climáticas: impactos sobre doenças de plantas no Brasil. Brasília: Embrapa, p. 25-73, 2008.

IPCC - Intergovernmental Panel on Climate Change - Annex I: Atlas of Global and Regional climate Projections Supplementary Material RCP4.5, van OLDENBORGH, G. J.; COLLINS, M.; ARBLASTER, J.; CHRISTENSEN, J. H.; MAROTZKE, J.; POWER, S. B.; RUMMUKAINEN, M.; ZHOU, T. (eds.). In: Climate change 2013: The physical science basis. Contribution of Working Group I to the Fifth Assessment Report of the Intergovernmental Panel on Climate Change. Stocker TF, et al. (ed.). Disponível em: <http://www.climatechange2013.org e http://www.ipcc. ch>. Acesso em: 07 mai. 2014.

MATTOS JÚNIOR, D.; NEGRI, J. D. de; FIGUEIREDO, J. O.; POMPEU JÚNIOR, J. Citrus: principais informações e recomendações de cultivo. Campinas: Instituto Agronômico de Campinas, 9 p., 2005.

MINUZZI, R. B.; CARAMORI, P. H. Mudanças climáticas e a demanda de água a irrigação do milho no Paraná. In: SIMPÓSIO BRASILEIRO DE AGROPECUÁRIA SUSTENTÁVEL, 2, 2010, Viçosa. Anais... Viçosa, MG: UFV, 2010.

MINUZZI, R. B.; FREDERICO, C. do A.; SILVA, T. G. F. da. Estimation of soybean agronomic performance in climatic scenarios for Southern Brazil. Revista Ceres, v. 64, n. 6, p. 567-573, 2017.

MINUZZI, R. B.; SEDIYAMA, G. C.; BARBOSA, E. da M.; MELO JÚNIOR, J. C. F. de. Climatologia do comportamento do período chuvoso da região Sudeste do Brasil. Revista Brasileira de Meteorologia, v. 22, n. 3, p. 338-344, 2007.

NEVES, M. F.; TROMBIN, V. G.; MILAN, P.; LOPES, F. F.; CRESSONI, F.; KALAKI, R. O retrato da citricultura brasileira. Ribeirão Preto: Markestrat, 138p., 2010. Disponível em: <http://www.citrusbr.com/ download/Retrato_Citricultura_Brasileira_MarcosFava.pdf>. Acesso em: 10 mai. 2019.

ORTEGA-FARIAS, S.; IRMAK, S.; CUENGA, R. H. Special issue on evapotranspiration measurement and modeling. Irrigation Science, v. 28, n. 1, p. 1-3, 2009.

PEREIRA, A. R. Balanço hídrico para irrigação de precisão aplicada em pomares. Campinas, SP: Fundag, 90 p., 2011.

POMMER, C. V.; BARBOSA W. The impact of breeding on fruit production in warm climates of Brazil. Revista Brasileira de Fruticultura, v. 31, n. 2, p. 612-635, 2009.

WU, P.; JIN, J.; ZHAO, X. Impact of climate change and irrigation technology advancement on agricultural water use in China. Climatic Change, v. 100, p. 797-805, 2010.

ZULIAN, A.; DÖRR, A.; ALMEIDA, S. C. Citricultura e agronegócio cooperativo no Brasil. Revista Eletrônica em Gestão, Educação e Tecnologia Ambiental, v. 11, n. 11, p. 2290- 2306, 2013.
REFERENCIAÇÃO

LIMA, E. P.; MINUZZI, R. B. Requerimento de irrigação para a laranja em cenários climáticos futuros no Norte e Noroeste Fluminense. Agrometeoros, Passo Fundo, v.27, n.1, p.165-172, set 2019.

Declaração: os trabalhos estão sendo publicados nesse número de AGROMETEOROS (v.27, n.1, set 2019) conforme foram aceitos pelo XXI Congresso Brasileiro de Agrometeorologia, realizado de 12 a 16 de agosto de 2019, em Catalão, Goiás, sem revisão editorial adicional da revista. 


\title{
Irrigation requirement for orange in future climate scenarios in the Northern and Northwestern Fluminense, Brazil
}

\author{
Evaldo de Paiva Lima ${ }^{1(*)}$ and Rosandro Boligon Minuzzi ${ }^{2}$ \\ ${ }^{1}$ Empresa Brasileira de Pesquisa Agropecuária (Embrapa Solos/UEP-Recife). Rua Antônio Falcão, 402, CEP 51020-240 Recife, PE, Brazil. \\ E-mail: evaldo.lima@embrapa.br \\ ${ }^{2}$ Universidade Federal de Santa Catarina (UFSC). Rodovia Admar Gonzaga, 1346, CEP 88034-001 Florianópolis, SC, Brazil. \\ E-mail: rosandro.minuzzi@ufsc.br \\ ${ }^{(*)}$ Corresponding author.
}

\section{ARTICLE INFO}

\section{Article history:}

Received 13 September 2019

Accepted 4 March 2020

\section{Index terms:}

production cycle

varieties

irrigation management
ABSTRACT

The objective of this study was to determine the irrigation water requirement for different orange varieties and climate scenarios in the Northern and Northwestern mesoregions of the state of Rio de Janeiro, Brazil. Climate data from Campos, Itaperuna and Santo Antônio de Pádua municipalities were used in the Cropwat 8.0 software to simulate the water requirement for irrigation by two methods, for the current climate (1981 to 2010) and in the climate scenarios based on projections of short (2016-2035) and medium (2046-2065) terms of the RCP4.5 and RCP8.5 scenarios of the Intergovernmental Panel on Climate Change (IPCC). The results showed increasing trends in water requirement for irrigation in the three groups of orange varieties, with the highest values occurring in the 'tardia' variety and in the Santo Antônio de Pádua municipality, both in the short and medium terms. However, given the insignificant increases in irrigation relative to the cycle length of the three orange varieties, the climate projected for the study region will still be sufficient to satisfy water needs for the three groups of orange varieties. 